\title{
Effects of a Severe Mountain Pine Beetle Epidemic in Western Alberta, Canada under Two Forest Management Scenarios
}

\author{
Richard R. Schneider, ${ }^{1}$ Maria Cecilia Latham, ${ }^{2}$ Brad Stelfox, ${ }^{3}$ Dan Farr, ${ }^{1}$ and Stan Boutin ${ }^{1}$ \\ ${ }^{1}$ Department of Biological Sciences, University of Alberta, Edmonton, AB, Canada T6G 2E9 \\ ${ }^{2}$ Fiera Biological Consulting Ltd., 200, 10318-82 Avenue, Edmonton, AB, Canada T6E 1Z8 \\ ${ }^{3}$ Forem Consulting Ltd., Box 805, Bragg Creek, AB, Canada TOL OKO
}

Correspondence should be addressed to Richard R. Schneider, contact@borealcentre.ca

Received 9 December 2009; Revised 8 February 2010; Accepted 12 April 2010

Academic Editor: Brian C. McCarthy

Copyright (c) 2010 Richard R. Schneider et al. This is an open access article distributed under the Creative Commons Attribution License, which permits unrestricted use, distribution, and reproduction in any medium, provided the original work is properly cited.

We used a simulation model to investigate possible effects of a severe mountain pine beetle (Dendroctonus ponderosae Hopkins) epidemic under two management scenarios in Alberta, Canada. Our simulated outbreak was based on the current epidemic in British Columbia, which may kill close to $80 \%$ of the province's pine volume. Our two management scenarios were conventional harvest and a pine-reduction strategy modeled on a component of Alberta's Mountain Pine Beetle Management Strategy. The pine strategy seeks to reduce the number of susceptible pine stands by $75 \%$ over the next 20 years through targeted harvesting by the forest industry. Our simulations showed that the pine strategy could not be effectively implemented, even if the onset of the beetle outbreak was delayed for 20 years. Even though we increased mill capacity by $20 \%$ and directed all harvesting to high volume pine stands during the pine strategy's surge cut, the amount of highly susceptible pine was reduced by only $43 \%$. Additional pine volume remained within mixed stands that were not targeted by the pine strategy. When the outbreak occurred in each scenario, sufficient pine remained on the landscape for the beetle to cause the timber supply to collapse. Alternative management approaches and avenues for future research are discussed.

\section{Introduction}

The mountain pine beetle (MPB) is currently in the outbreak phase of an infestation cycle throughout much of its range in British Columbia, Canada. Outbreaks are also occurring in other parts of MPB range in western North America and the beetle is expanding into areas previously considered beyond its natural ecological range [1].

For the first time in recorded history, large numbers of beetles from British Columbia have crossed the Rocky Mountains and are attacking lodgepole pine (Pinus contorta) forests along the foothills of Alberta [2]. The size and intensity of the current outbreak in British Columbia have been so great that control efforts have been overwhelmed [3]. The British Columbia Ministry of Forests predicts that $77 \%$ of the province's pine volume will be killed by the time the infestation subsides [4].

It is possible that Alberta's nascent outbreak will come to resemble the current epidemic in British Columbia. Many of the factors that led to the outbreak in British Columbia are increasingly prevalent in Alberta: a warming climate, fire suppression leading to extensive mature pine stands, limited access, administrative and economic constraints, and infection sources with the potential for rapid population expansion [2, 5]. However, the climate in Alberta's foothills is generally cooler than in the interior of British Columbia, and much of the pine in Alberta's foothills grows in mixed stands [1]. Managers hope that these factors will sufficiently slow the spread of MPB in Alberta so that control efforts will be able to maintain beetle populations at endemic levels.

The Government of Alberta has implemented a MBP Management Strategy intended to contain the infestation and maintain the long-term timber supply [2]. Single-tree and stand-level harvest of infested trees are the primary beetle control measures and are supplemented with pheromone treatments to concentrate beetles before and after harvest. There is also a preventive pine reduction strategy that seeks to reduce the number of susceptible pine stands by $75 \%$ over 
the next 20 years through targeted harvesting by the forest industry [2]. A temporary increase in the Annual Allowable Cut (AAC) is permitted during this time; however, long-term even flow requirements are to be maintained.

The core elements of the Alberta MPB Management Strategy - control, salvage, and prevention-all involve forest harvesting. Given that the mills in the region have capacity limitations, allocating harvest effort among these management options requires a tradeoff decision. The effects of beetle and management activities on environmental and economic indicators further complicate the decision [6]. We simulated the effects of a severe MPB epidemic in western Alberta, in terms of changes to a suite of forest management outcome measures, under two management scenarios: conventional harvest and a preventive pine reduction strategy. Our objective was to describe the potential outcomes of these alternative management approaches over the medium and longer term.

\section{Methods}

2.1. The ALCES Model. We used an existing simulation model, ALCES, (see http://www.alces.ca/.) to investigate the effects of a MPB outbreak and associated management responses in Alberta. ALCES is designed to track the cumulative effects of ecological processes and human activities under alternative management scenarios. The user must supply the initial state of the landscape and provide quantitative assumptions concerning natural disturbances, industrial activities, and regeneration trajectories for each disturbance type. Based on values provided, the model tracks and updates the state of the landscape in time steps of one year for as long as requested. When considering only forest harvesting and regeneration, the model is functionally equivalent to the aspatial timber supply models used by forestry companies for long-term harvest planning [7]. However, ALCES has greater capacity for incorporating natural and human origin disturbances than timber supply models and can provide a greater range of ecological output measures.

In ALCES, the landscape can be stratified into multiple independently tracked classes. For example, a forest land base can be stratified into several stand types and age classes, and different harvest and regeneration strategies can be applied to each stratum. Because we were specifically interested in tracking the effects of the MPB, we used forest inventory data to stratify stands containing pine into three categories: Pure_Pine ( $>80 \%$ pine); High_Pine (50\%-79\% pine); and Low_Pine ( $<50 \%$ pine). High_Pine and Low_Pine were mixed stands that contained pine in combination with hardwoods, other softwoods, or both. The remaining merchantable forest stands were classified as Hardwood ( $>80 \%$ hardwood) or Non-pine Softwood ( $>80 \%$ Non-pine softwood). Stands were also stratified into 20-year seral stage classes.

The disturbance and regeneration modules in ALCES are user specified. We used the insect disturbance module to specify the type and age of stands subject to MPB infestation as well as the temporal trajectory of the outbreak (i.e., ha disturbed in each year of the outbreak). The model has the capacity to allow stands to transition to a different stand type

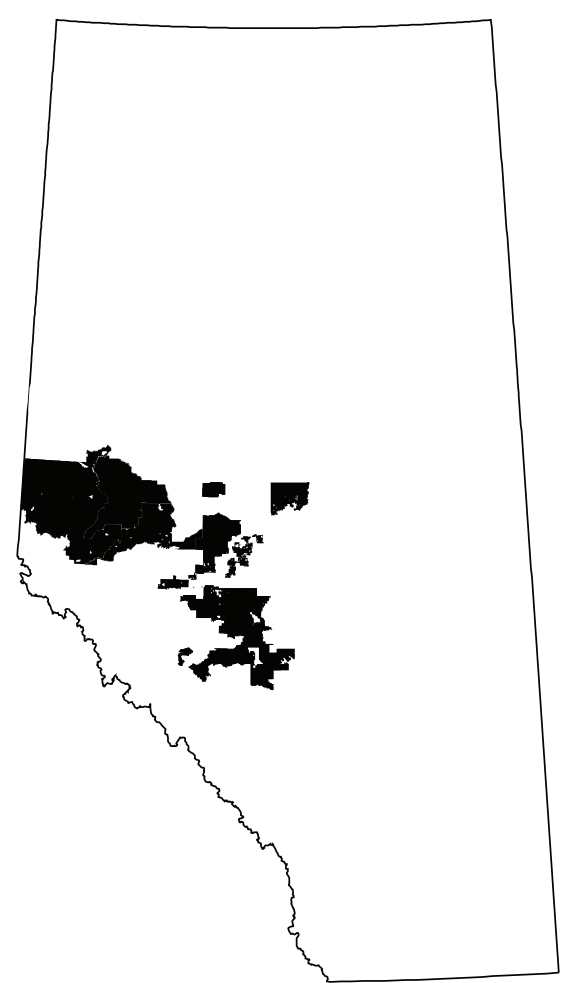

FIgure 1: The province of Alberta, showing the location of our study area.

after disturbance. The age of stands after disturbance can also be defined by the user (i.e., reset to the zero age class is not necessary).

2.2. Modelling Experiment. Our study area is comprised of six forest management areas in the foothills of central Alberta (Figure 1). The total area is 3.6 million ha, of which 2.5 million ha is forested. Lodgepole pine, white spruce (Picea glauca) and aspen (Populus tremuloides) are the three dominant tree species, each accounting for approximately one-third of the total area of forested land.

We did not model the population dynamics of the MPB per se, but the projected effects of the beetle on pine stands. We assumed, as a worst-case scenario, that $80 \%$ of pine stands would be attacked during the outbreak. This is consistent with projections for the MPB outbreaks occurring in many parts of British Columbia $[4,8]$. This high level of attack could not be achieved in our model without allowing all age classes of pine to be susceptible to attack, except those under 20 years. Because forest harvesting resets the age class to zero, an increase in the rate of forest harvesting (i.e., a surge cut) would reduce the pool of stands available to the MBP in the model. The temporal trajectory of our outbreak was based on a composite of the projected trajectories of outbreaks in 22 Timber Supply Areas in British Columbia (Figure 2; [4]). In stands that were attacked, we assumed that $75 \%$ of the pine volume would be killed [9].

All infected stands were salvaged, to the extent that sufficient mill capacity was available (see below). The 


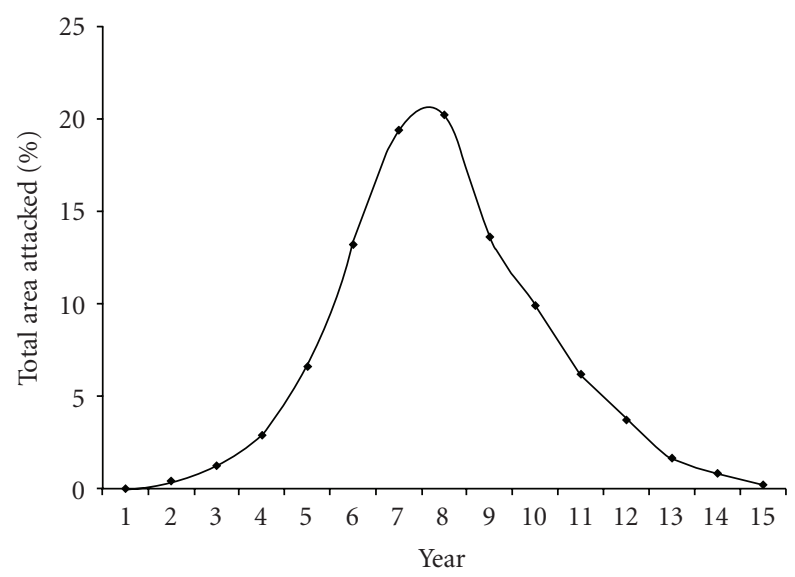

Figure 2: Temporal trajectory of the simulated MPB outbreak, expressed as the annual percentage of the total area of pine attacked.

salvage of infected stands was given priority over scheduled harvesting operations because the removal of infected stands serves as a primary beetle control measure in the Alberta MPB Management Strategy [2]. To maintain tractability, salvage operations were assumed to occur within one year of MPB attack. Those stands that could not be salvaged because of inadequate mill capacity (this occurred during the peak years of the outbreak) were left to regenerate naturally.

In our simulation, the regeneration process was same whether a stand was salvaged or harvested conventionally. Stand age was reset to zero and stands then followed standard growth and yield curves provided by the forest companies in our study area. We assumed that the regeneration efforts applied to salvaged stands would ensure that no changes in stand type would occur.

Infested stands that were not salvaged regenerated naturally. In mixed stands we accounted for the change in internal composition and volume resulting from pine mortality but left the age of the stand unchanged (Table 1). In High_Pine stands, the loss of $75 \%$ of the pine volume forced a transition to Low_Pine or Non-pine Softwood, depending on the composition of the original stand. Low_Pine stands stayed as Low_Pine or transitioned to either Hardwood or Non-pine Softwood, again depending on the original stand composition. In the case of Pure_Pine, we treated the beetle attack as a stand-replacing disturbance and reset stands to age class zero. We assumed that stands on dry sites and mesic sites with low productivity would grow back to Pure_Pine and stands on productive mesic sites would grow back to Low_Pine (Table $1 ;[10,11])$.

We assumed that the MPB epidemic in Alberta would occur within the next 20 years, as an extension of the outbreak currently occurring in British Columbia. Given that the timing of the outbreak cannot be reliably predicted we simulated two versions of the MPB epidemic-one in which the outbreak began immediately and another in which the outbreak was delayed by 20 years. For comparison, we also conducted a simulation in which there was no MPB outbreak. Each of the three MPB scenarios was run in combination with two management scenarios: conventional harvest $(\mathrm{CH})$ and pine strategy (PS). In the $\mathrm{CH}$ scenario, conventional harvest rules were applied, as described in the Detailed Forest Management Plans of forestry companies in our study area. The PS scenario was based on the pine strategy component of the Alberta MPB Management Strategy, which seeks to reduce the number of susceptible pine stands by $75 \%$ over the next 20 years through directed harvesting by the forest industry [2]. To simulate the pine strategy we focused all harvesting on Pure_Pine and High_Pine stands for the first 20 years. In all other respects, PS was the same as $\mathrm{CH}$. The six combined scenarios were as follows.

(1) $\mathrm{CH}-\mathrm{None} \mathrm{CH}$ with no MPB outbreak.

(2) PS-None: PS with no MPB outbreak.

(3) $\mathrm{CH}$-Immed: same as $\mathrm{CH}-\mathrm{None}$, but with a MPB outbreak in year one.

(4) PS-Immed: same as PS-None, but with a MPB outbreak in year one.

(5) $\mathrm{CH}$-Delay: same as $\mathrm{CH}-\mathrm{None}$, but with a MPB outbreak in year 21.

(6) PS-Delay: same as PS-None but with a MPB outbreak in year 21 .

The models simulated 100 years of activity. We assumed that MPB attack and forest harvesting were the only forms of disturbance on the landscape (i.e., other forms of industrial development and natural disturbance were not simulated) and that only one MPB outbreak would occur over the course of the simulation. The target AAC for softwoods was set at 4.1 million $\mathrm{m} 3$, based on data provided by the forestry companies in our study area. We assumed that mill capacity and AAC could be temporarily increased by $20 \%$ to accommodate the surge in wood flow from the pine strategy and from salvage related to the MPB outbreak. Wood volume harvested during the surge cut was applied against long-term even flow requirements, but as per current provincial policy, salvage wood was not. The AAC was not recalculated after the MPB attack.

\section{Results}

3.1. Scenarios without MPB. In both $\mathrm{CH}-\mathrm{None}$ and PS-None the softwood AAC was achieved throughout the entire 100year simulation. The relative proportion of forest types did not change in these runs because all harvested stands were regenerated to their original stand type. Fifty-eight percent of the forest was classified as old-growth forest at the start of the simulation (where old-growth is defined as stands older than 80 years for hardwood and older than 100 years for all other stand types). By year 70, the percentage of forest classified as old growth had declined to $22 \%$ and $25 \%$ in $\mathrm{CH}-\mathrm{None}$ and PS-None, respectively. The declines in old growth were relatively balanced among forest types in PSNone, but in $\mathrm{CH}-\mathrm{None}$ the declines were most pronounced in the hardwood and mixedwood forest types (Figure 3).

PS-None was unable to achieve its objective of reducing the amount of susceptible pine forest by $75 \%$. The area 
TABLE 1: Transition matrix used to determine the fate of stands after MPB attack in the absence of salvage operations.

\begin{tabular}{lclc}
\hline \multicolumn{1}{c}{ Before MPB Attack } & & & \multicolumn{1}{c}{ After MPB Attack } \\
Forest Type & Area (ha) & Forest Type & Proportion $^{\text {a }}$ \\
\hline Pure_Pine (pine $\geq 80 \%$ ) & 637,132 & Pure_Pine & 0.29 \\
& & Low_Pine & 0.71 \\
High_Pine (pine 50\%-79\%) & 304,191 & Non-pine Softwood & 0.80 \\
& & Low_Pine & 0.20 \\
Low_Pine (pine $<50 \%$ ) & 366,507 & Hardwood & 0.10 \\
& & Low_Pine & 0.56 \\
Hardwood (pine $<20 \%)$ & & Non-pine Softwood & 0.34 \\
Non-pine Softwood (pine $<20 \%)$ & 770,374 & Hardwood & 1.00 \\
\hline
\end{tabular}

${ }^{a}$ All calculations were done at the stand level using forest inventory data. For each forest type we determined the composition of stands before attack, applied the transition rules described in the text, and then reclassified the stands based on their new composition.

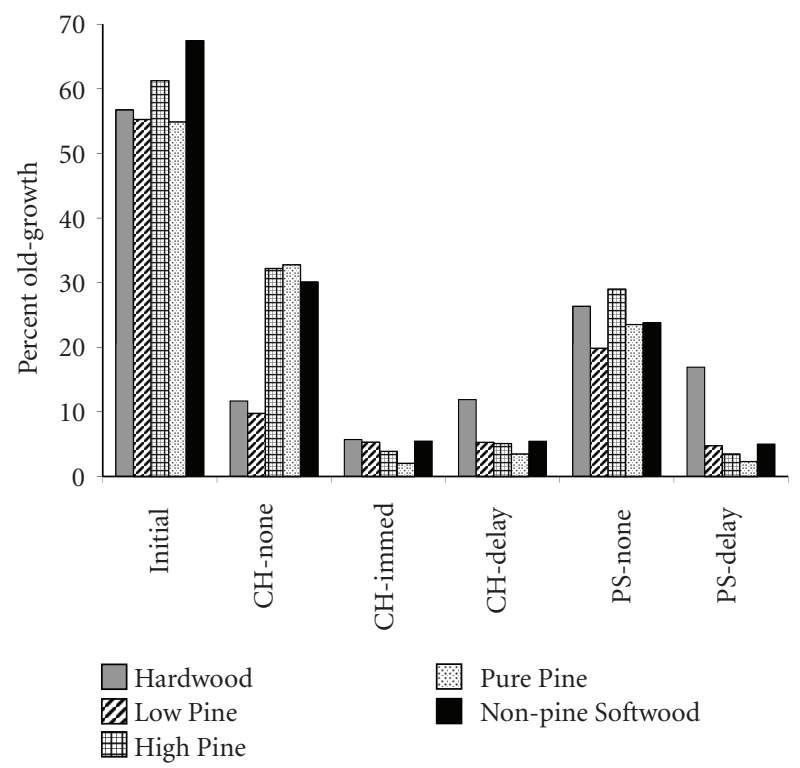

Figure 3: Representation of old-growth forest in the study area at year 70 of the simulation for each of the management scenarios, by stand type.

of Pure_Pine and High_Pine older than 60 years (i.e., the highly susceptible stands) was only reduced by $43 \%$ at the conclusion of the surge cut in year 20. Over the same period $\mathrm{CH}-$ None reduced the area of susceptible stands by $5 \%$.

\subsection{Scenarios with an Immediate MPB Outbreak. The $\mathrm{CH}$} and PS scenarios were functionally similar when subjected to an immediate MPB attack. Harvesting operations in both cases focused on salvage by year three of the simulation. Once the outbreak subsided, harvesting efforts in both scenarios switched largely to non-pine forest types because little merchantable pine remained on the landscape.

In both immediate outbreak scenarios, the beetle attacked $39 \%$ of the forested land base. Constraints on mill capacity meant only $57 \%$ of the merchantable pine volume killed by the MPB was salvaged. Stands that were

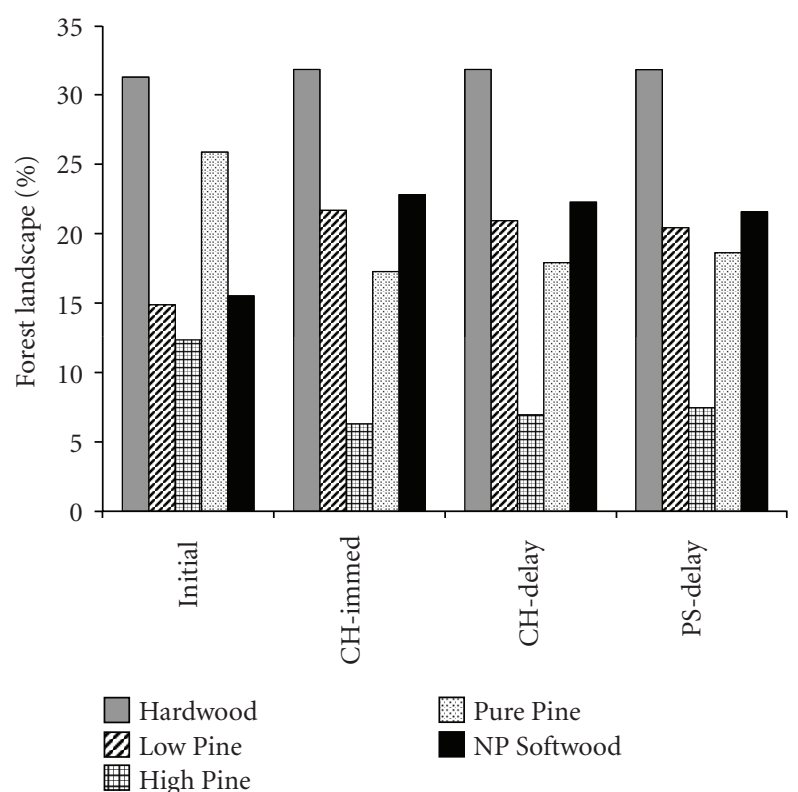

FIgURE 4: Composition of the forest land base in the study area at year 70. Scenarios without MPB are not shown because forest composition does not change in the absence of MPB infestation.

not salvaged were subjected to the model's transition matrix (Table 1) resulting in changes in the composition of the forest. Pure_Pine and High_Pine declined by $33 \%$ and $49 \%$, respectively (Figure 4).

After the outbreak, in both scenarios, the softwood AAC was maintained mostly through the harvest of Low_Pine and Non-pine Softwood stands. This land base could only sustain the original rate of harvest until year 60 , at which time a shortage of timber precipitated a $75 \%$ decline in softwood harvest volume. Only $7 \%$ of the forest was in the old-growth category at the point of collapse, and 5\% remained at year 70 (Figure 3).

3.3. Scenarios with a Delayed MPB Outbreak. The proportion of the land base attacked by the MBP in CH-Delay and PSDelay was $37 \%$ and $31 \%$, respectively. Of the merchantable 


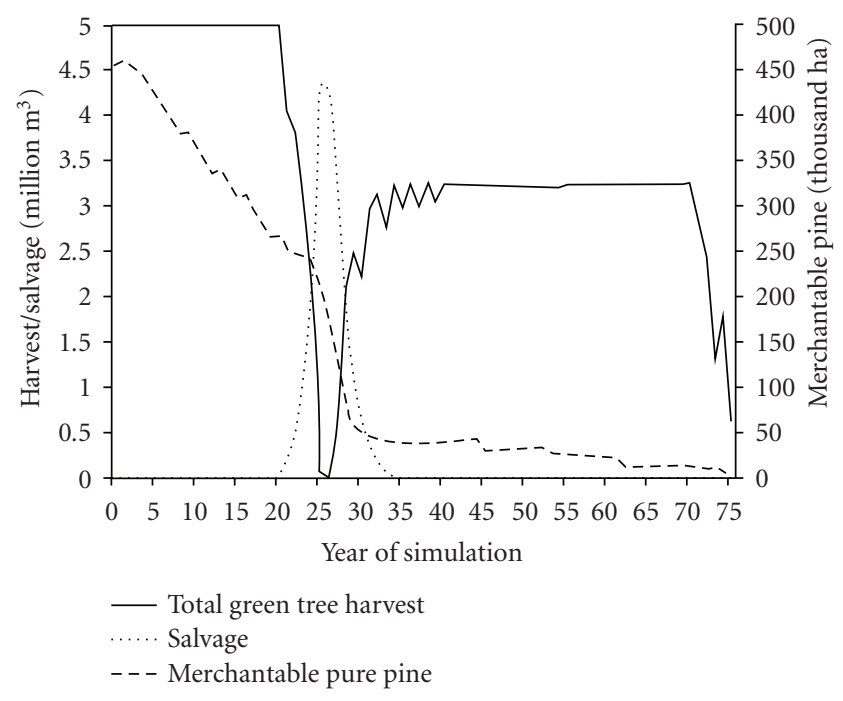

Figure 5: Temporal dynamics of the PS-Delay scenario showing the total softwood harvest excluding salvage (green tree), softwood salvage, and the remaining area of merchantable pure pine stands (i.e., those older than 80 years).

pine volume killed by the beetle, 59\% was salvaged in $\mathrm{CH}$-Delay and $97 \%$ in PS-Delay. Approximately $30 \%$ of the stands attacked by the beetle in PS-Delay were stands regenerating from the pine strategy's surge harvest. Since these stands were old enough to be attacked by the MBP, but too young to be considered for salvage, the rate of salvage (which only considers eligible stands) was artificially inflated.

Softwood harvest collapsed in both delayed outbreak scenarios, but occurred about ten years later than in the immediate outbreak scenarios. The key features of the temporal dynamics of the PS-Delay scenario are presented in Figure 5. The changes in forest composition observed in $\mathrm{CH}$ Delay and PS-Delay were not appreciably different than those observed in CH-Immed (Figure 4). The percentage of oldgrowth forest at year 70 was $7 \%$ and $8 \%$ for the $\mathrm{CH}$-Delay and PS-Delay scenarios, respectively (Figure 3 ).

\section{Discussion}

Our study suggests that the current rate of softwood harvest in our study area cannot be maintained if Alberta's pine beetle infestation follows a trajectory similar to the outbreak in British Columbia. To do so, forestry companies would have to increase their harvest of non-pine species to levels that are not sustainable. According to our simulations, maintaining current harvest levels after the MPB attack would lead to a general collapse in the softwood timber supply in 60-70 years. If other forms of disturbance such as wildfire and petroleum development had been included in our simulations, the collapse in timber supply would have occurred even earlier.

The proactive pine strategy, meant to reduce the number of highly susceptible stands, could not be effectively implemented in the face of an immediate MPB outbreak. By year three of our simulation of the pine strategy, harvesting operations were focused on salvage instead of green-tree harvest. Following the outbreak, almost no merchantable pine remained to be harvested. The pine strategy was, therefore, no different than conventional harvest in terms of what material was harvested (beetle-killed pine).

Although we did not model it, the endpoint would have been the same if harvesting under the pine strategy had continued to focus on green trees. This is because harvesting operations and the MPB compete for the same target species, and the near-total removal of pine from the land base is the ultimate outcome, regardless of the source of mortality (in our worst-case scenario).

The simulated pine strategy failed to prevent the collapse in wood supply even if the epidemic stage of the infestation was delayed for 20 years, for two main reasons: not enough pine had been removed from the land base to prevent substantial tree mortality from the MPB, and the pine strategy itself contributed to the timber shortfall. Mill capacity constraints limited the pine strategy's removal of highly susceptible pine to $43 \%$. Additional pine trees remained within Low_Pine stands that were not targeted by the pine strategy. Finally, stands harvested at the beginning of the pine strategy's surge cut were old enough to be attacked by the peak of the delayed MPB outbreak.

The harvest rules in our conventional harvest scenario were designed to produce an even-aged forest with maximum stand age set by the rotation interval. As a result, the proportion of old-growth forest in the conventional harvest scenario decreased from $58 \%$ at the start of the simulation to $22 \%$ by year 70 . When the MPB was added to the system, the amount of old growth declined to $8 \%$ or less in both the conventional harvest and pine strategy scenarios. All stand types were affected because the pine killed by the beetle caused a general shortfall in timber supply that forced the model to increase the rate of harvest of other species to maintain the AAC. A reduction in old-growth forest of this magnitude would significantly reduce habitat supply for species dependent on older forest, potentially reducing their abundance and range.

The harvest rules in our simulation specified that stands be regenerated to their original type. As a result, the composition of the land base in the absence of MPB stayed the same. But when the MPB was added to the system, up to $37 \%$ of the Pure_Pine and High_Pine stands transitioned to Low_Pine and Non-pine Softwood. These transitions occurred in stands that were left to regenerate naturally, because they were either too young to be salvaged or there was insufficient mill capacity to process them.

In our simulations, we assumed that all pure and mixed stands containing pine older than 20 years will support the same rate of MPB attack and spread. This assumption is inconsistent with studies that have shown that stand age and pine density are important determinants of susceptibility to MPB [12-14]. But without this assumption, our simulations could not have achieved the $80 \%$ reduction in pine volume projected for British Columbia [8]. Anecdotal reports from British Columbia suggest that the conventional rules concerning stand susceptibility are indeed overridden when a MPB epidemic is of very high intensity. 
An important area of research over the next few years will be to determine the actual rate of MBP attack and spread in Alberta and to use this information to undertake more refined projections than those used in our study. It may well be that, in Alberta, the combination of younger stands (via the pine strategy), lower density of pine in mixed forests, and cooler temperatures will collectively serve to slow MPB population growth to a manageable level—or at least, to avoid severe loss of timber.

Our simulations show that forestry companies lack the capacity for fully implementing the surge cut prescribed by the pine strategy. Even though we increased mill capacity by $20 \%$ and completely stopped harvesting stands with low pine volume, the 20-year surge cut reduced the amount of susceptible pine by only $43 \%$.

The economic case for increasing mill capacity by even $20 \%$ is weak, given the current glut of pine on the market due to the MPB outbreak in British Columbia and the high likelihood of a fall-down in future wood supply [8]. Furthermore, some companies will continue to harvest hardwood and Non-pine softwood stands to meet specific needs, reducing the available capacity for harvesting pine. The implication is that the amount of forest harvested under the actual pine strategy is likely to be lower than the $43 \%$ in our simulations, further weakening the potential effect of this strategy.

Given the inability of the pine strategy to achieve its stated objectives, and given that the surge cut itself contributes to the future shortage in wood supply, alternative management options should be explored. For example, consideration should be given to converting the pine land base to mixed forest, in what we call the mixedwood approach, to increase its resistance to the effects of the MPB $[15,16]$. In this approach, all harvest capacity would focus on pure pine stands, both infested and uninfested, and regeneration efforts would convert as many as possible to mixed stands. Existing mixed stands that are attacked by MPB would not be salvaged. In contrast, harvest efforts under the government's pine strategy are allocated more broadly and regeneration efforts aim to maintain pure pine sites as pure pine.

The mixedwood approach offers several advantages over the existing pine strategy. First, by focusing on a smaller land base (pure pine only) it is more achievable with existing mill capacity. Second, if left standing, the non-pine volume in infested mixed stands will help maintain continuity of the timber supply, especially during the midterm [8]. The loss of volume in mixed stands may even be partially offset by increased growth of the non-pine trees because of reduced competition. Third, in contrast to pure pine stands, mixed stands attacked by MPB will retain or increase in structural complexity [17]. Protecting these stands from harvest and focusing instead on pure pine stands will retain more structure on the land base. This would help support ecological integrity by maintaining habitat supply and reducing erosion. It is worth noting that the mixedwood approach does not confer the aforementioned benefits if pine stands, particularly pure pine stands, are not destined to be killed by the MPB.

\section{Conclusions}

Given that the MPB is now widely distributed across the eastern slopes of the Rocky Mountains of Alberta and British Columbia, the likelihood of overwintering mortality affecting all beetle populations in Alberta is low [9]. Moreover, the odds of such an event will decrease over time because of the general warming trend that is now underway [1]. This suggests that the MPB may be in Alberta to stay. That said, the trajectory of the infestation may well be less intense than the worst-case scenarios modeled.

If the outbreak in Alberta does follow the trajectory observed in British Columbia, then management interventions will have little impact and a catastrophic outcome is likely, at least socioeconomically [4]. In this case, care should be taken to ensure that social and environmental values are not jeopardized by management actions themselves. For example, the AAC should be immediately recalculated to prevent a total collapse in wood supply and the loss of oldgrowth forest observed in our simulations. On the other hand, if the outbreak proceeds at a much slower pace due to local climatic and pine density factors in combination with management efforts, then a positive socioeconomic outcome may be possible. In this case, additional field research and modeling studies would help to determine the best way of allocating harvest efforts to slow the rate of spread of the beetle and minimize its overall impact [18-20].

\section{Acknowledgments}

The authors thank their forest industry partners for providing them with forest inventory data and information on their harvesting operations. They also thank John Stadt and colleagues at Alberta Sustainable Resource Development for providing them with the government's perspectives on MBP management. Funding for this study was provided by the Government of Canada as part of the Mountain Pine Beetle Program administered by Natural Resources Canada and by NSERC-ACR Chair in Integrated Landscape Management at the University of Alberta.

\section{References}

[1] A. L. Carroll, J. Regniere, J. A. Logan, S. W. Taylor, B. Bentz, and J. A. Powell, Impacts of Climate Change on Range Expansion by the Mountain Pine Beetle. Mountain Pine Beetle Initiative Working Paper 2006-14, Natural Resources Canada, Canadian Forest Service, Victoria, British Columbia, Canada, 2006.

[2] Alberta Sustainable Resource Development, Mountain Pine Beetle Management Strategy, Alberta Sustainable Resource Development, Edmonton, Alberta, Canada, 2007, http://www.srd.gov.ab.ca/forests/health/.

[3] N. C. Coops, J. A. Timko, M. A. Wulder, J. C. White, and S. M. Ortlepp, "Investigating the effectiveness of Mountain Pine Beetle mitigation strategies," International Journal of Pest Management, vol. 54, no. 2, pp. 151-165, 2008.

[4] A. Walton, J. Hughes, M. Eng, et al., Provincial-Level Projection of the Current Mountain Pine Beetle Outbreak: Update of the infestation projection based on the 2007 Provincial Aerial 
Overview of Forest Health and Revisions to the "Model (BCMPB.v5), B.C. Ministry of Forests and Range, Victoria, British Columbia, Canada, 2008, http://www.for.gov.bc.ca/ hre/bcmpb/.

[5] K. F. Raffa, B. H. Aukema, B. J. Bentz, et al., "Cross-scale drivers of natural disturbances prone to anthropogenic amplification: the dynamics of bark beetle eruptions," BioScience, vol. 58, no. 6, pp. 501-517, 2008.

[6] J. Kimmins, B. Seely, C. Welham, and A. Zhong, Possible Forest Futures: Balancing Biological and Social Risks in MPB Epidemics. Mountain Pine Beetle Initiative Working Paper 2005-11, Natural Resources Canada, Canadian Forest Service, Victoria, British Columbia, Canada, 2005.

[7] Forestry Corp, ALCES, "Timber supply validation: comparison of ALCES and Woodstock/Stanley," Prepared for Alberta Environment and the Alberta Forest Products Association, Edmonton, Alberta, Canada, 2002.

[8] B.C. Ministry of Forests and Range, Timber Supply and the Mountain Pine Beetle Infestation in B.C. 2007 Update, B.C. Ministry of Forests and Range, Victoria, British Columbia, Canada, 2007.

[9] M. Eng, A. Fall, J. Hughes, T. Shore, B. Riel, and P. Hall, Provincial Level Projection of the Current Mountain Pine Beetle Outbreak: An Overview of the Model (BCMPB) and Draft Results of Year 1 of the Project, Natural Resources Canada, Canadian Forest Service, Victoria, British Columbia, Canada, 2004.

[10] R. Astrup, K. D. Coates, and E. Hall, "Recruitment limitation in forests: lessons from an unprecedented mountain pine beetle epidemic," Forest Ecology and Management, vol. 256, no. 10, pp. 1743-1750, 2008.

[11] J. J. Stadt and K. J. Greenway, Lodgepole Pine Stand Dynamics in Alberta Following Mountain Pine Beetle, Alberta Sustainable Resource Development, Edmonton, Alberta, Canada, 2008.

[12] J. A. Schenk, R. L. Mahoney, J. A. Moore, and D. L. Adams, "A model for hazard rating lodgepole pine stands for mortality by mountain pine beetle," Forest Ecology and Management, vol. 3, pp. 57-68, 1980.

[13] T. L. Shore and L. Safranyik, Susceptibility and Risk-Rating Systems for the Mountain Pine Beetle in Lodgepole Pine Stands. Information Report No. BCX-336, Forestry Canada, Pacific Forestry Centre, Victoria, British Columbia, Canada, 1992.

[14] T. L. Shore, L. Safranyik, and J. P. Lemieux, "Susceptibility of lodgepole pine stands to the mountain pine beetle: testing of a rating system," Canadian Journal of Forest Research, vol. 30, no. 1, pp. 44-49, 2000.

[15] R. Whitehead and G. Russo, Beetle-Proofed Lodgepole Pine Stands in Interior British Columbia Have Less Damage from Mountain Pine Beetle. Information report BC-X-402, Natural Resources Canada, Canadian Forest Service, Victoria, British Columbia, Canada, 2005.

[16] C. R. Nitschke and J. L. Innes, "Integrating climate change into forest management in South-Central British Columbia: an assessment of landscape vulnerability and development of a climate-smart framework," Forest Ecology and Management, vol. 256, no. 3, pp. 313-327, 2008.

[17] J. Dordel, M. C. Feller, and S. W. Simard, "Effects of mountain pine beetle (Dendroctonus ponderosae Hopkins) infestations on forest stand structure in the southern Canadian Rocky Mountains," Forest Ecology and Management, vol. 255, no. 10, pp. 3563-3570, 2008.

[18] N. Björklund, B. S. Lindgren, T. L. Shore, and T. Cudmore, "Can predicted mountain pine beetle net production be used to improve stand prioritization for management?" Forest Ecology and Management, vol. 257, no. 1, pp. 233-237, 2009.
[19] W. A. Nelson, A. Potapov, M. A. Lewis, A. E. Hundsdörfer, and F. He, "Balancing ecological complexity in predictive models: a reassessment of risk models in the mountain pine beetle system," Journal of Applied Ecology, vol. 45, no. 1, pp. 248-257, 2008.

[20] M. K. Trzcinski and M. L. Reid, "Effect of management on the spatial spread of mountain pine beetle (Dendroctonus ponderosae) in Banff National Park," Forest Ecology and Management, vol. 256, no. 6, pp. 1418-1426, 2008. 

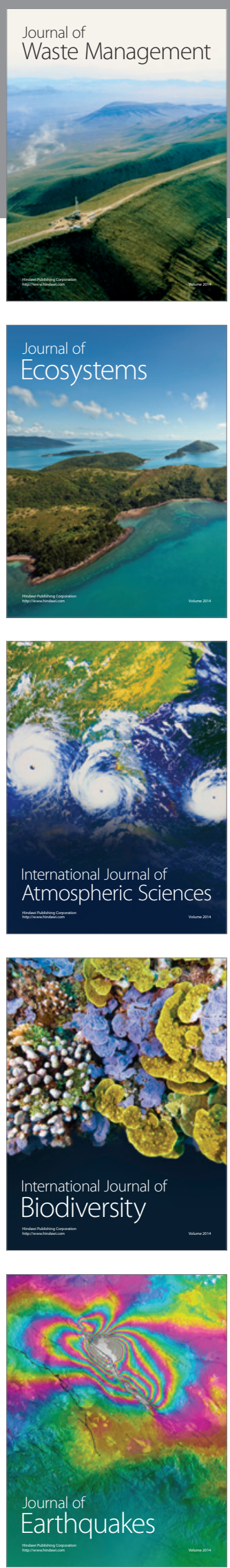
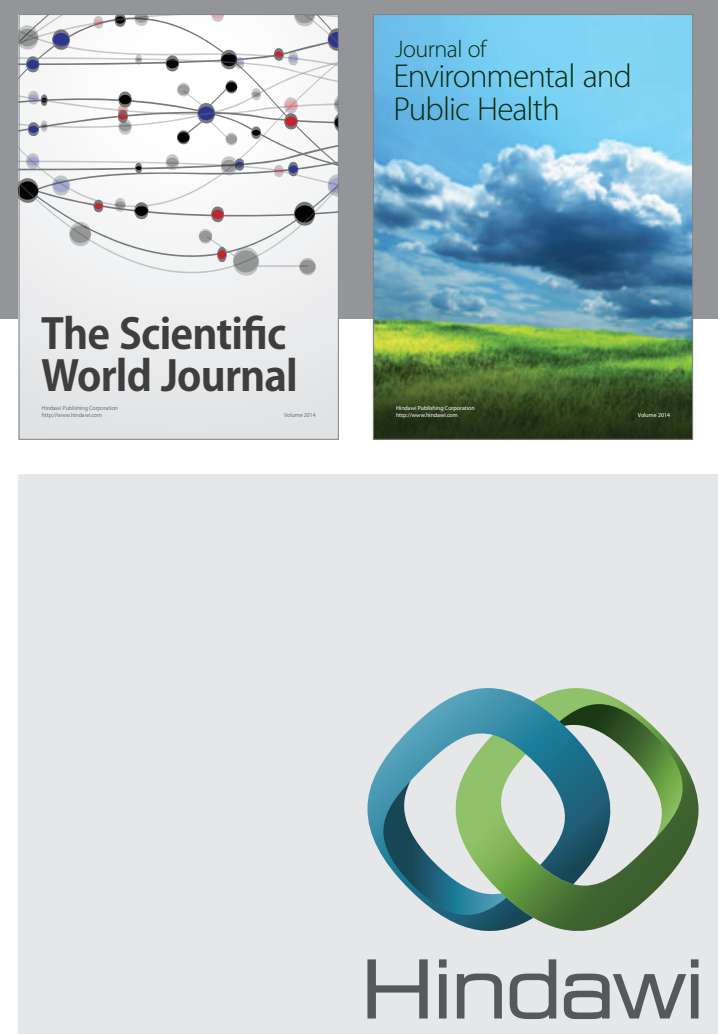

Submit your manuscripts at

http://www.hindawi.com
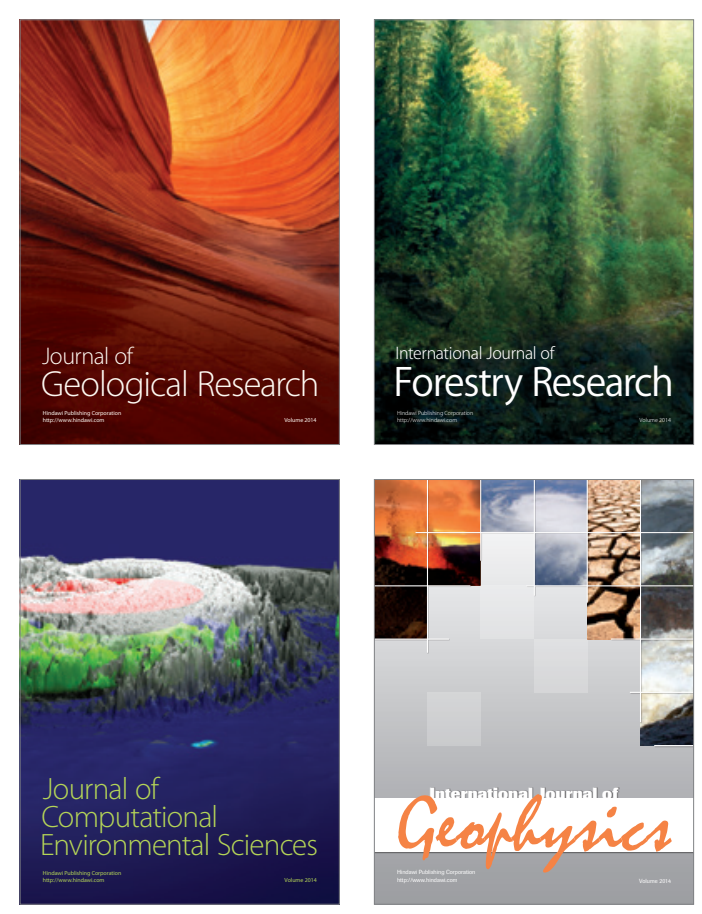
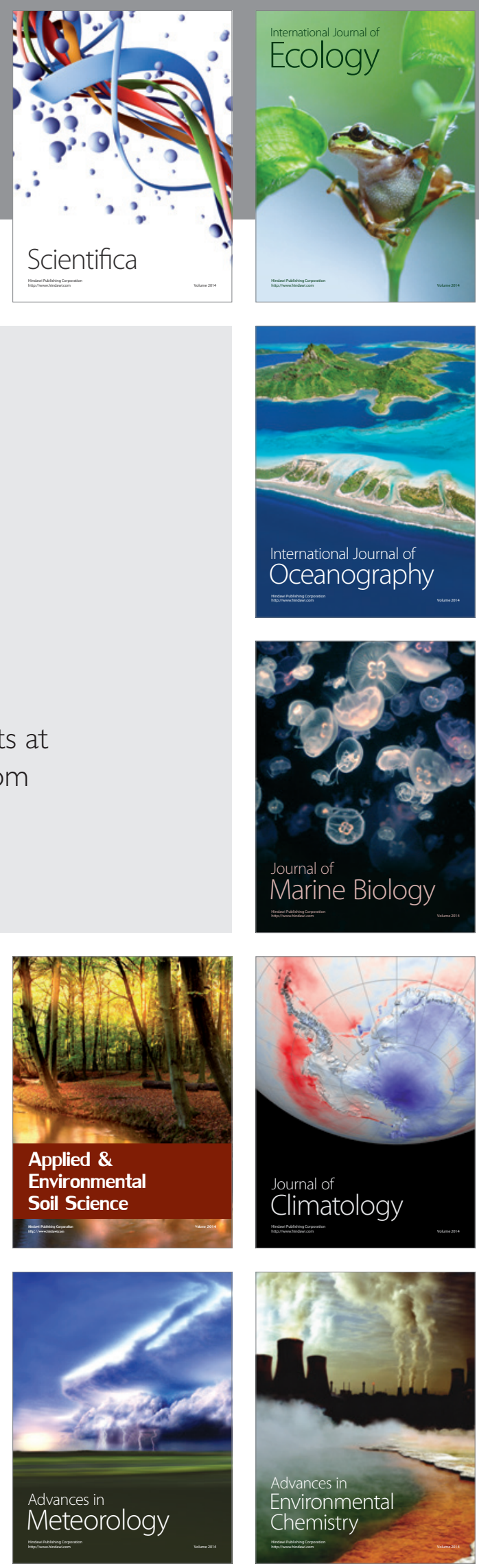